\title{
Effect of metformin on apoptosis induction in ovarian cancer cells
}

\author{
Aneta Rogalska ${ }^{1}$, Ewa Forma ${ }^{2}$, Piotr Ciesielski², Magdalena Bryśs ${ }^{2}$, Anna Krześlak², Agnieszka Marczak ${ }^{1}$ \\ ${ }^{1}$ Department of Thermobiology, Faculty of Biology and Environmental Protection, University of Lodz, Poland \\ 2Department of Cytobiochemistry, Faculty of Biology and Environmental Protection, University of Lodz, Poland
}

\begin{abstract}
Introduction: Ovarian cancer is one of the most difficult problems in gynecologic oncology and the search for new drugs effective in the treatment of this kind of cancer, especially in cases resistant to current forms of therapy, remains a challenging priority.

The aim of the study was to analyze the effect of metformin on apoptosis and the BIRC5 gene expression in ovarian cancer cell line SKOV-3. The BIRC5 gene encodes survivin protein.

Material and methods: SKOV-3 cells were treated with metformin $(10 \mathrm{mM})$. Apoptotic changes in studied cells were analyzed by double staining using a mixture of fluorochromes - Hoechst 33258/propidium iodide (PI). The expression of the BIRC5 gene at the mRNA level was analyzed using the real-time PCR technique.

Results: Treatment of cells with metformin causes changes in the cell shape from oval to spindle and leads to the separation of the cells from the monolayer. Furthermore, metformin induces apoptosis and necrosis of ovarian cancer cells. A statistically significant increase in the number of apoptotic cells after 48 and 72 hours' treatment with metformin relative to a control cells seems to be correlated with a decrease in the expression of the BIRC5 gene at the mRNA level.
\end{abstract}

Conclusions: Metformin seems to be a promising agent, whose use in ovarian cancer patients may contribute to improving the effectiveness of therapy.

Key words: metformin, ovarian cancer, SKOV-3, apoptosis, BIRC5, survivin.

\section{Introduction}

Metformin (1,1-dimethylbiguanide hydrochloride), a biguanide derivative, is a widely prescribed antihyperglycemic drug which is used as the first-line therapy for diabetes mellitus type 2. Metformin primary actions include inhibition of hepatic glucose production and reduction of insulin resistance in peripheral tissue, leading to enhanced glucose uptake and utilization in skeletal muscle [1]. Metformin has been shown to act as a tumor growth inhibitor, at least in part by upregulation of AMP-activated protein kinase (AMPK) activity and by downstreaming suppression of signaling through the mammalian target of rapamycin (mTOR) [2-5]. It has been shown that the anticancer effect of metformin has a close relationship with the apoptosis induction [6-9]. In studies concerning triple negative breast cancers (TNBC, triple-negative breast cancer) it was found that metformin caused the cell cycle arrest in the S phase and induction of apoptosis [10]. Similar results showing apoptosis induction by metformin in pancreatic cancer cell line ECC-1 were obtained by Wang et al. [11] in relation to the apoptosis induction in pancreatic cancer cell line ASPC-1, BXPC-3, PANC-1 and SW1990, exposed to metformin.
It was also found that metformin-induced apoptosis is associated with PARP (poly-ADP-ribose polymerase) cleavage and activation of caspase- $3,-8$, and -9 in a time- and dose-dependent manner [11]. In the case of endometrial cancer cell line ECC-1, metformin also enhances the effects of other anticancer drugs such as paclitaxel (PTX) [12].

Survivin is a protein acting as an apoptosis inhibitor and is involved in cell cycle regulation, especially at the transition from the $\mathrm{G} 1$ to $\mathrm{S}$ phase. This protein is encoded by the BIRC5 gene (baculoviral IAP repeat containing $5)$, which is located on the long arm of chromosome 17 (17q25.3). Survivin expression in non-neoplastic tissues is limited to the normal thymocytes, hematopoietic CD34+ stem cells and colon epithelial cells while survivin overexpression is observed in many types of malignant cells [13].

This protein controls the caspase-dependent and caspase-independent apoptosis [14]. In the cells receiving the signal to apoptosis, survivin inhibits caspase 3 , 7 and 9 [15].

Currently, in the literature there are no reports on the relationship between metformin, survivin and apoptosis. In view of the above, the aim of this study was to analyze 
the effect of metformin on apoptosis and the BIRC5 gene expression in ovarian cancer cell lines SKOV-3.

We used ovarian cancer cells for our studies because this kind of cancer is one of the most difficult problems in gynecologic oncology [16] and the search for new drugs effective in the ovarian cancer treatment, especially in cases resistant to current forms of therapy, remains a challenging priority.

\section{Material and methods \\ Cell culture}

The human SKOV-3 cell line was obtained from the American Type Culture Collection (ATCC) based in Rockville, MD, USA. Cells were grown as a monolayer in sterile polystyrene dishes (Nunc, Denmark). Cells in the logarithmic phase of growth were used in all experiments. The cells were routinely screened for the Mycoplasma contamination and were maintained as a monolayer in RPMI 1640 (Immuniq, Poland) supplemented with 10\% heat inactivated FBS (Cambrex, Basel, Switzerland), penicillin $(10 \mathrm{U} / \mathrm{ml})$ and streptomycin $(50 \mu \mathrm{g} / \mathrm{ml})$. The cells were grown at $37^{\circ} \mathrm{C}$ in a $5 \% \mathrm{CO}_{2}$ atmosphere in a culture medium and were passaged after covering about $80-90 \%$ of the dish.

\section{Spectrophotometric determination of cells survival affer treatment with metformin}

The SKOV-3 cell line survival after metformin treatment (Sigma-Aldrich, Corp., St. Louis, MO, USA) was determined by the spectrophotometric method (17) in 96-well plates. We determined $I C_{50}$ parameter using a computer program ED50plus v1.0 (http://www.free-downloadscenter.com/download/ed50plus-v1-0-2434.html).

\section{Double staining with Hoechst 33258 and propidium iodide}

For determination of apoptotic changes, by double staining, cells were incubated with a concentration of $10 \mathrm{mM}$ metformin, for 24, 48 and 72 hours. Then, a suspension of cells having a density of $1 \times 10^{5}$ cells/ $\mathrm{ml}$ was prepared and a mixture of fluorochromes - Hoechst 33258/propidium iodide (PI) (Sigma-Aldrich, Corp., St. Louis, MO, USA) was added. The concentration of the individual fluorochromes was as follows: Hoechst $33258-0.13 \mathrm{mM}, \mathrm{PI}-0.23 \mathrm{mM}$ and the cells were incubated at room temperature for 10 min in total darkness. The cells were then applied to glass slides and at least 300 cells were counted under the fluorescence microscope (Olympus IX 70, Japan), using UV filter (360-370 nm) [18]. The percentage of cells following fraction was calculated: live - blue-gray uniform color; early apoptosis - deep blue with a distinct chromatin condensation, cells in late apop- tosis - pink, with a purple stained nucleus and chromatin segregation and necrotic cells were red. The total number of cells in the sample was taken as $100 \%$. Representative areas of cells stained at $48 \mathrm{~h}$ of incubation with metformin were chosen for photographic documentation.

\section{RNA isolation and CDNA synthesis}

Total RNA was isolated using Trizol ${ }^{\circledR}$ Reagent (Sigma-Aldrich Corp., St. Louis, MO, USA) according to the manufacturer's protocol and quantified spectrophotometrically. First-strand cDNAs were obtained by reverse transcription of $1 \mu \mathrm{g}$ of total RNA using the High Capacity cDNA Reverse Transcription Kit (Life Technologies, USA) following the manufacturer's protocol.

\section{Quantitative real-time RT-PCR (RT-qPCR)}

Real-time PCR gene expression analysis of the target gene (BIRC5) was performed using TaqMan ${ }^{\circledR}$ Gene Expression Assays (Applied Biosystems) according to the manufacturer's instructions. The HPRT1 (hypoxanthine phosphoribosyltransferase 1) gene was used as an internal control. The assay numbers for these genes were as follows: BIRC5 - Hs04194392 s1, HPRT1 - Hs02800695 $\mathrm{m} 1$. Each PCR reaction was performed in a $10 \mu \mathrm{l}$ volume that included $5 \mu$ l of $2 \times$ TaqMan Universal PCR MasterMix (Applied Biosystems), $4.5 \mu$ l of water diluted cDNA template $(50 \mathrm{ng})$ and $0.5 \mu \mathrm{l}$ of $\operatorname{TaqMan}^{\circledR}$ Gene Expression Assay consisting of a pair of unlabeled PCR primers and TaqMan probe with a FAM ${ }^{\mathrm{TM}}$. The RT-qPCR reaction was carried out using the Mastercycler ep realplex (Eppendorf). Relative RNA quantification was performed using the $\Delta \mathrm{Ct}$ method. $\Delta \mathrm{Ct}\left(\mathrm{Ct}_{\text {BIRC5 }}-\mathrm{Ct}_{\text {HPRT1 }}\right)$ values were recalculated into relative copy number values (number of BIRC5 mRNA copies per 1000 copies of HPRT1 mRNA).

\section{Statistical analysis}

Statistical analysis was performed using the STATISTICA version 11.0 (StatSoft, Poland). $\Delta$ Ct values obtained from quantitative real-time PCR were recalculated into relative copy number values. Obtained results were not normally distributed (Kolmogorov-Smirnov test) and therefore, nonparametric statistical tests were used for analyzing the results. A value of $p<0.05$ was considered statistically significant.

\section{Results}

\section{Changes in the morphology of cell line SKOV-3 offer treatment with metformin}

The spectrophotometric method with MTT allowed to determine the IC50 value of metformin (14 mM). 
For further experiments, the concentration of $10 \mathrm{mM}$ was selected corresponding to the MET survival of more than $60 \%$ relative to control cells, not treated with the drug. This is a concentration corresponding to the physiological dose used in the women tumors treatment [19].

Figure 1 shows the morphology of cells treated with metformin (10 mM, 24-72 h) observed with the use of a phase contrast microscope (Olympus IX 70, Japan). Changes in the cell shape were dependent on the time of incubation. It was noted that in the case of control cells (not treated with metformin), over time, the number of cells in the visual field increased. After 72 hours, almost all the dish was covered with cells.
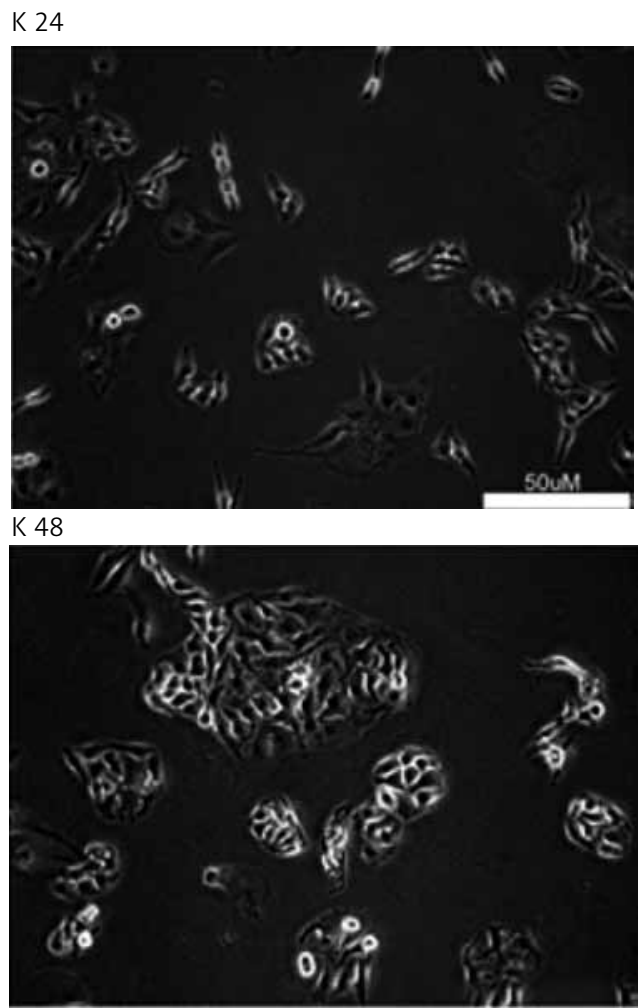

K 72

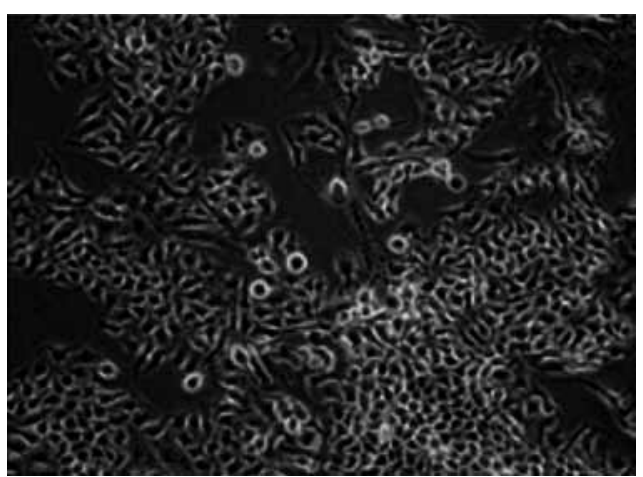

In contrast, in samples treated with metformin, the number of cells increased more slowly, which confirms the anti-proliferative properties of the tested compound. Metformin induced elongation and changes in the cell shape from oval to spindle and separation of the cells from the surface of the monolayer (Fig. 1).

\section{Apoptotic changes induced by metformin}

The double staining method with fluorochromes Hoechst 33258 and propidium iodide allowed to observe morphological changes in the nucleus, associated with the different phases of cell death. Four fractions of the cells were identified: live cells, in the early phase of

MET 24

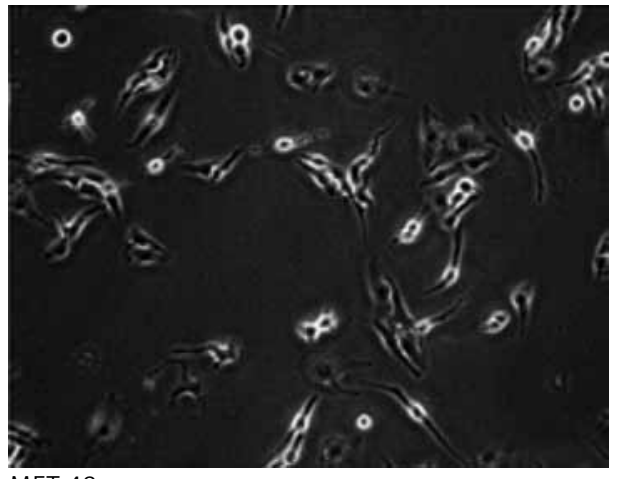

MET 48

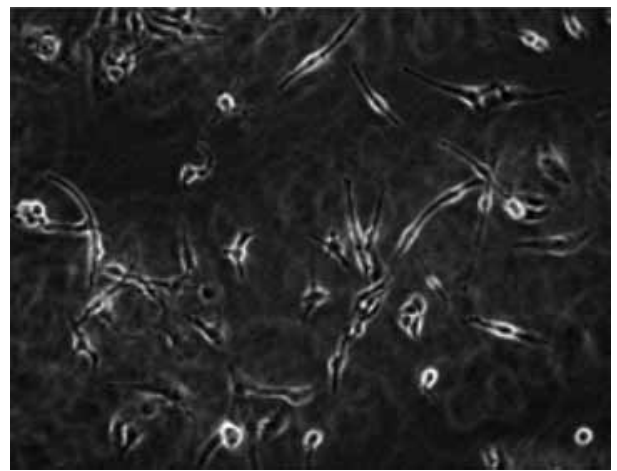

MET 72

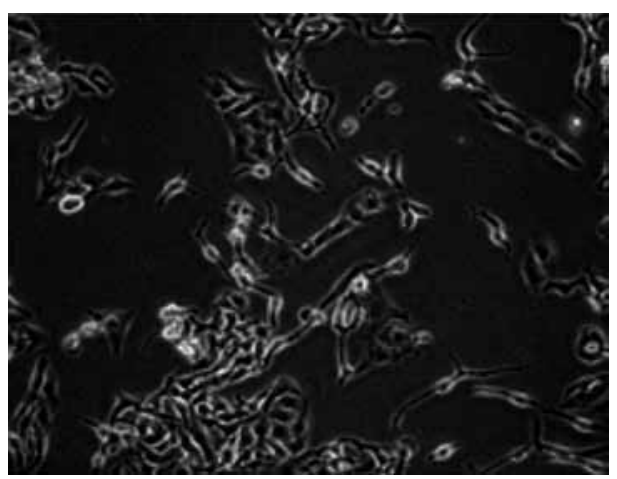

Fig. 1. The morphology of control cells and cells treated with metformin (10 mM, 24-72 hrs.). Pictures were taken using an inverted microscope equipped with a camera, in a phase contrast (Olympus IX70, Japan) (scale $=50 \mu \mathrm{m}$ ). $\mathrm{K}-$ control cells, not treated with metformin, MET 24, 48 and 72 - cells treated with metformin for 24, 48 and 72 hours 
apoptosis, late stage apoptosis and necrotic cells. Sample images of control cells and incubated with metformin are shown in Figure 2. After treatment the cells with metformin changes in the structure, size and shape of the cell nucleus, such as chromatin condensation and marginalization accompanying early apoptosis and the appearance of apoptotic bodies, typical changes of late apoptosis were noted. There was also observed damage of the cell membrane, allowing propidium iodide to penetrate into the cell nucleus and color it red - a typi- cal hallmark of necrosis. The quantitative analysis of individual fractions is presented in Figure 3. It was shown that metformin induced both apoptotic and necrotic cell death. After $24 \mathrm{~h}$ incubation with the drug, the number of apoptotic and necrotic cells was similar. However, after 48 and 72 hours, apoptosis was the predominant fraction. The percentage of apoptotic cells was $18.8 \%$ and $24.3 \%$, respectively for 48 and $72 \mathrm{~h}$ and the percentage of necrotic cells was $10.2 \%$ and $14.2 \%$, respectively. These differences were statistically significant (Fig. 3).

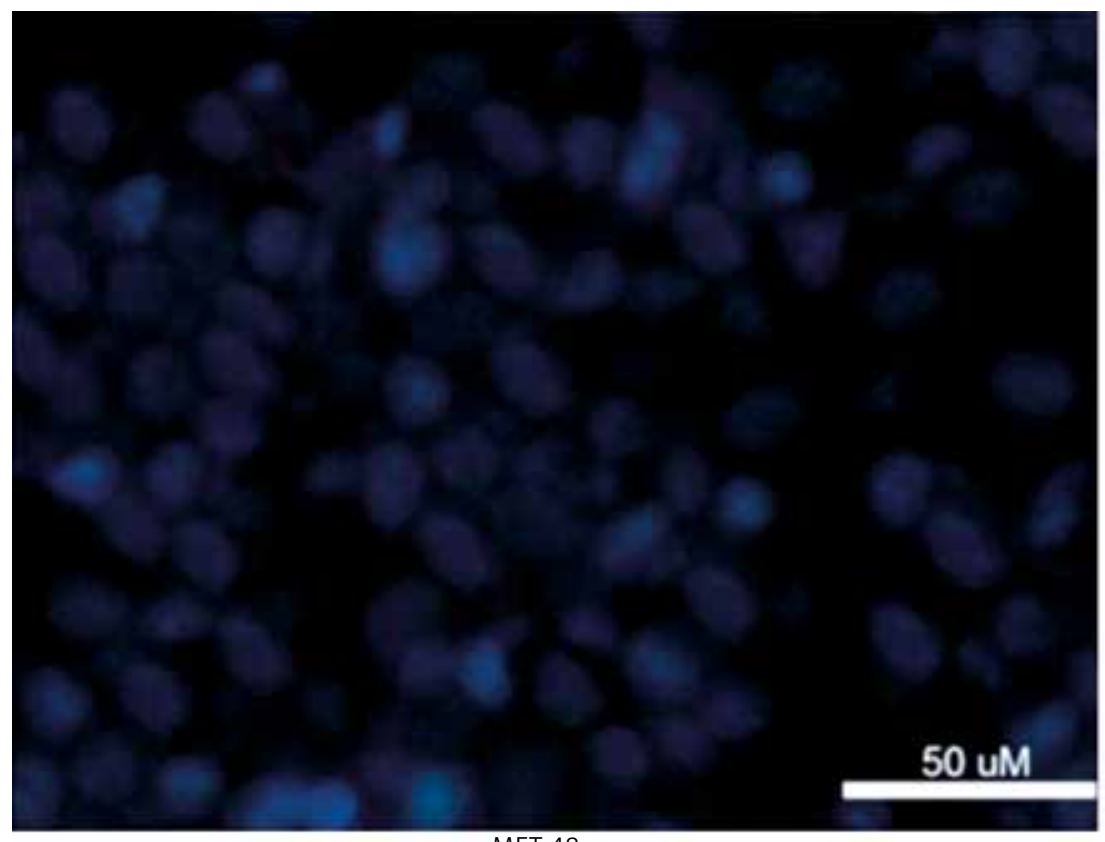

MET 48
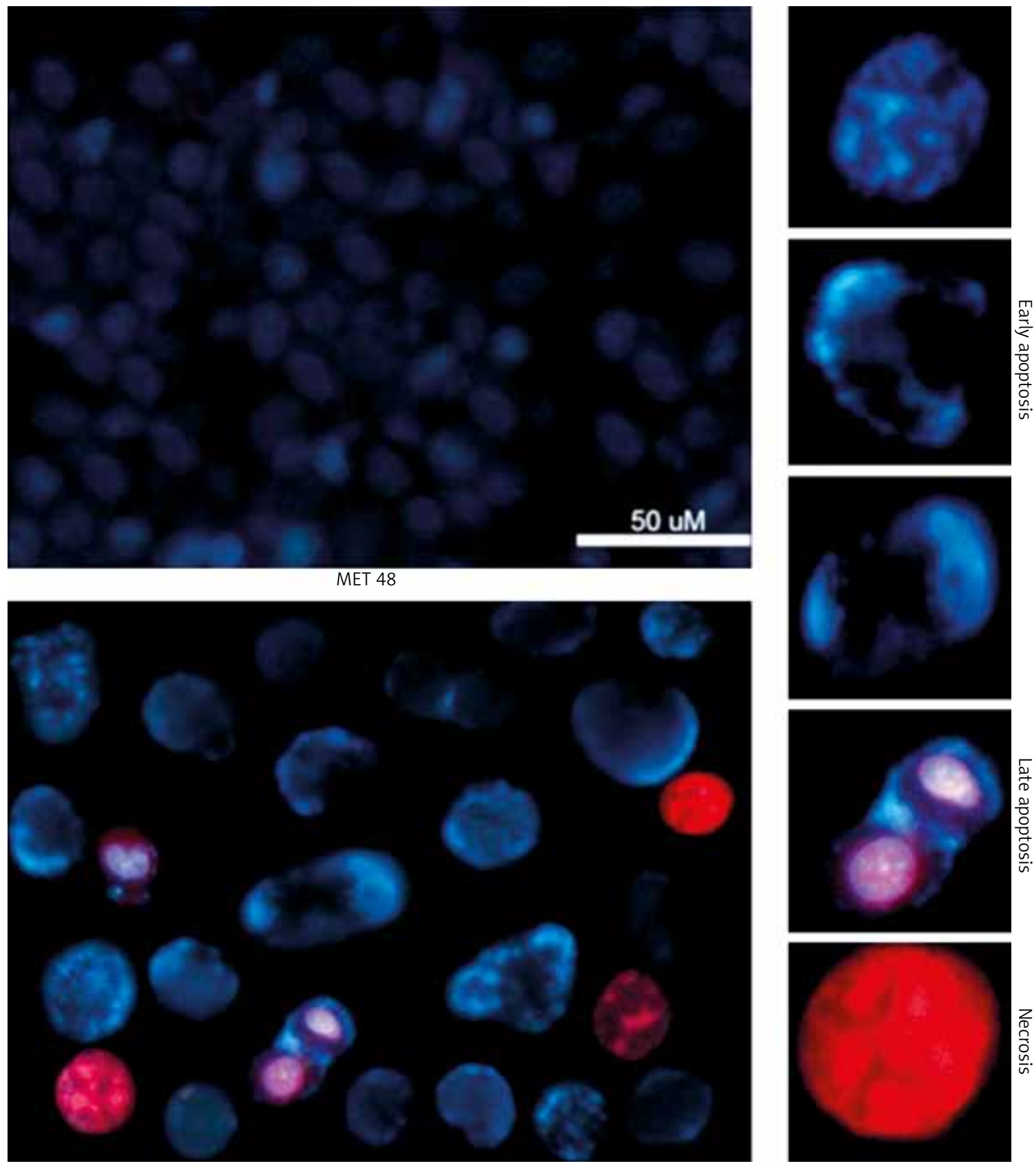

Fig. 2. Morphological changes, typical of apoptosis and necrosis observed after 48 hours of incubation of the SKOV-3 cell line with metformin (10 mM). Observation was carried out using a fluorescence microscope (Olympus IX70, Japan). The right panel shows the selected cells in the early and late stages of apoptosis and necrosis 


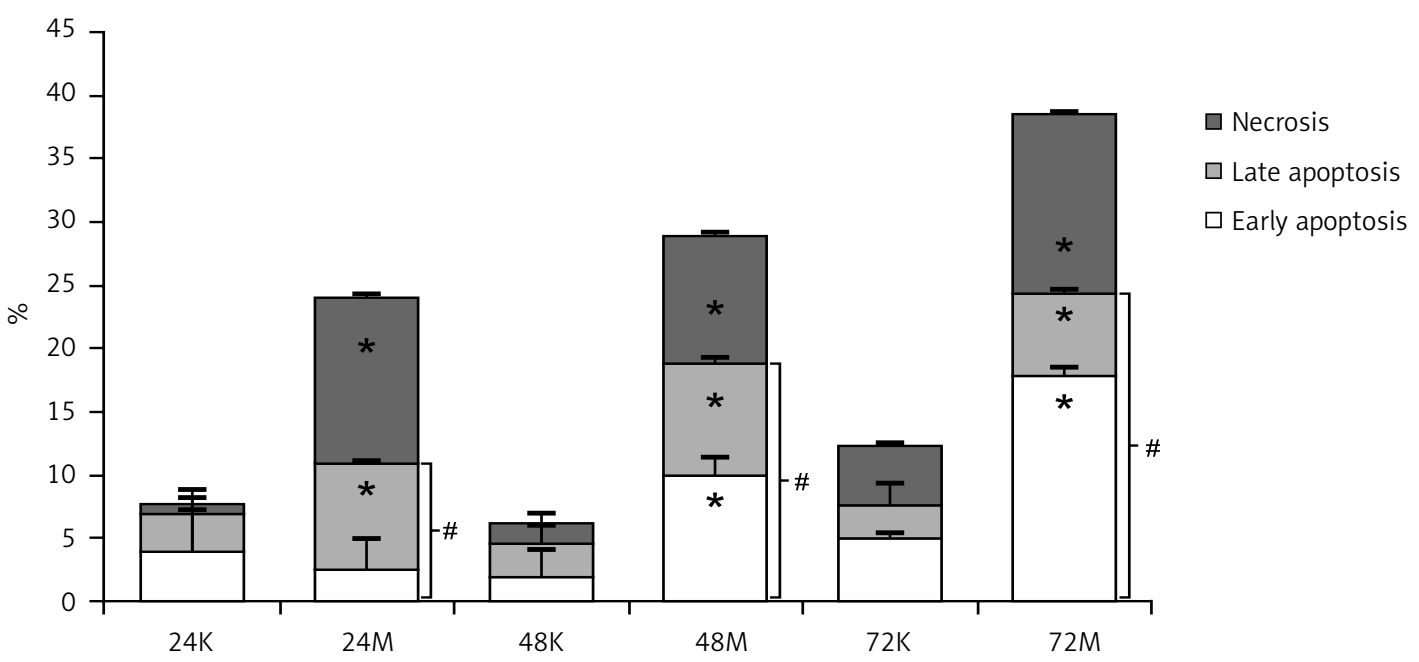

Fig. 3. Double staining of the SKOV-3 cell line with Hoechst 33258/PI mixture (metformin at a concentration of $10 \mathrm{mM}$ ). Results are presented as $\pm \mathrm{SD}$ of four experiments. $\left(^{*}\right) p<0.05$ statistically significant differences between trials treated and not treated with metformin, $(\#) p<0.05$ statistically significant differences in the number of apoptotic cells in samples fraction incubated with metformin and control cells

\section{Effect of metformin on the BIRC5 gene expression}

The BIRC5 mRNA expression was analyzed in ovarian cancer cell line SKOV-3 treated with $10 \mathrm{mM}$ metformin solution. Gene expression was investigated in cells exposed to the compound for 24, 48 and 72 hours. Metformin untreated cells were used as a control. In the case of the BIRC5 mRNA expression, a statistically significantly higher level was found in cells incubated with metformin for 24 and 48 hours as compared to cells incubated for 72 hours. In untreated cells, the BIRC5 mRNA expression level was the highest after 48 hours from the start of the experiment, whereas the lowest value was reached at 72 hours of the experiment. It was also observed that after 48 and 72 hours of incubation, metformin decreased the BIRC5 mRNA expression level, compared to the control.

A diagram illustrating the relative expression of BIRC5 mRNA in metformin-treated and untreated ovarian cancer cell line SKOV-3 is shown in Figure 4.

\section{Discussion}

The maintenance of homeostasis in a multicellular organism is associated with the balance between such processes as proliferation, differentiation and cell death. Ovarian cancer is most frequently diagnosed at an advanced stage $[20,21]$. In the diagnosis of changes in the differentiation of malignant cancer, it is very important to check the family history, biochemical markers and ultrasonography image (USG) [22]. Progression of the disease might be related to immune response to the developing cancer [23]. Moreover, recent studies show that diabetes is conducive not only to cardiovas- cular diseases, nephropathy, retinopathy and neuropathy, but also to the development of many types of cancers. Recent data have shown that metformin, a drug commonly used in diabetic patients, can significantly decrease the incidence rate and death risk associated with malignant cancers [24]. However, the evidence of the effects of metformin on ovarian cancer is still limited and inconclusive. Metformin was introduced into the clinical practice in the 1950s for the treatment of type II diabetes mellitus but presently it is often used for the treatment of other conditions associated with insulin resistance, especially polycystic ovarian syndrome $[25,26]$. Current studies report positive effects in

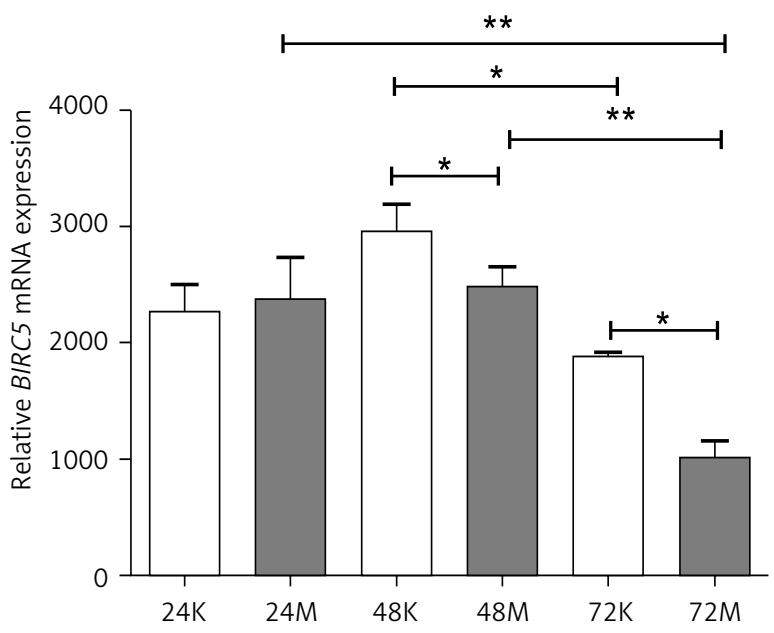

Fig. 4. Relative $B I R C 5$ mRNA expression in metformin-treated and untreated ovarian cancer cell lines SKOV-3 after 24, 48 and 72 hours. $\mathrm{K}$ - control cells not treated with $10 \mathrm{mM}$ metformin, $M$ - cells treated with metformin. $\left({ }^{\star}\right) p<0.05$; $\left.{ }^{(\star}\right) p<0.01-$ statistically significant differences 
the treatment of gynecological cancers such as ovarian, endometrial and cervical cancer [27]. For ovarian cancer, preclinical studies have shown that metformin can inhibit the proliferation of cancer cell lines. It was found that approximately $50 \%$ of diabetic patients receiving metformin survived for 5 years longer than nondiabetic patients who did not receive metformin $[28,29]$.

Our study confirms cytotoxic and anti-proliferative properties of metformin on the SKOV-3 cells. Similar studies were performed on the OVCAR- 3 and OVCAR-4 cell lines, where metformin induced significant proliferation inhibition in a dose- and time-dependent manner. The drug induces an increase in the AMPK activity. Moreover, upregulation of AMPK was associated with a reduced phosphorylation of p70S6K and S6 kinase. In turn, these downregulations are known to decrease mRNA translation and protein synthesis, that would explain the anti-neoplastic effect [3]. In the metformin treatment of mouse ovarian cancer, an increase in the AMPK level was observed. Inhibition of mTOR pathway by AMPK was also shown, and so was reduction of the expression of cyclin D1, which in turn inhibits the proliferation of ovarian cancer cells [30].

Necrosis and apoptosis are considered as two main mechanisms leading to cell death. Apoptosis, also called programmed, physiological, active, suicide or altruistic cell death, is a form of cell death in which a programmed sequence of events involving activation of specific genes leads to cell elimination. This process is essential for embryonic development, in the elimination of old cells having the mutated genetic material, as well as atrophy of the hormonal dependent tissues (e.g. peeling of the mucosa during the menstrual cycle). In normal conditions, cells are constantly being produced and apoptosis takes place to eliminate a similar number of older cells, so that the final number of cells is constant [6].

Excessive cells resistance to apoptosis may be associated with neoplastic transformation, while too extensive cell death due to apoptosis or necrosis may result in degenerative diseases and neurological disorders [31].

In this article we have evaluated the level of apoptosis in ovarian cancer cells treated by metformin. Our results were confirmed by other researchers. Metformin induced apoptosis in OVCAR-3 and OVCAR-4 cell lines in an AMPK-independent manner and provoked a cell cycle arrest in the $S$ and $G 2 / M$ phase. Apoptosis in OVCAR-3 and OVCAR-4 cells was induced by activating caspases 3/7, down-regulating Bcl-2 and Bcl-xL expression, and up-regulating Bax and Bad expression [32].

It has been shown that survivin plays a key role in the apoptosis modulation.

In the cell lines, an increased expression of this protein is associated with inhibition of apoptosis induced by factors stimulating external and internal apoptotic pathways [33]. The expression of survivin was not observed in the mitochondria of normal cervical, colorec- tal and kidney cells, whereas this protein was detected in mitochondria of breast cancer cells [34]. In response to cell death-inducing agents, the mitochondrial survivin level decreases because the protein is released into the cytoplasm, where it prevents the activation of caspases and thereby inhibits apoptosis [15].

According to a published study by Nair et al. [35], the molecular basis of the metformin and survivin relationships are associated with a decreased expression of Sp transcription factors. The pancreatic cancer cell lines Panc1, and Panc28 L3.6pL treated with metformin showed a reduced Sp1, Sp3 and SP4 protein expression and a decreased expression of proto-oncogenes, which are regulated by these transcription factors (e.g. Bcl-2, survivin, cyclin D1, vascular endothelial growth factor and its receptors, and fatty acid synthase).

In the liver cancer gene therapy, anti-apoptotic activity of survivin was inhibited by use of antisense RNA, which resulted in induction of apoptosis and an increase in cell sensitivity to chemotherapy $[36,37]$.

The present study confirmed that apoptosis caused by metformin treatment of ovarian cancer cells SKOV-3 is associated with alteration in the BIRC5 mRNA expression. A statistically significant increase in the number of apoptotic cells after 48 and 72 hours' treatment with metformin relative to control cells seems to be correlated with a decreased expression of the BIRC5 gene at the mRNA level. According to the literature, and on the basis of our results, metformin, a compound that reduces the BIRC5 gene expression appears to be a promising agent that may increase the therapy effectiveness of ovarian cancer patients.

\section{Disclosure}

Authors report no conflicts of interest.

\section{References}

1. Franciosi M, Lucisano G, Lapice $E$, et al. Metformin therapy and risk of cancer in patients with type 2 diabetes: systematic review. PLoS One 2013; 8: e71583.

2. Dowling RJ, Zakikhani M, Fantus IG, et al. Metformin inhibits mammalian target of rapamycin-dependent translation initiation in breast cancer cells. Cancer Res 2007; 67: 10804-10812.

3. Gotlieb WH, Saumet J, Beauchamp MC, et al. In vitro metformin antineoplastic activity in epithelial ovarian cancer. Gynecol Oncol 2008; 110 : 246-250.

4. Zakikhani M, Dowling R, Fantus IG, et al. Metformin is an AMP kinasedependent growth inhibitor for breast cancer cells. Cancer Res 2006; 66: 10269-10273.

5. Leclerc GM, Leclerc GJ, Kuznetsov JN, et al. Metformin induces apoptosis through AMPK-dependent inhibition of UPR signaling in ALL lymphoblasts. PLoS One 2013; 8: e74420.

6. Ben Sahra I, Le Marchand-Brustel Y, Tanti JF, et al. Metformin in cancer therapy: a new perspective for an old antidiabetic drug? Mol Cancer Ther 2010; 9: 1092-1099.

7. Tomic T, Botton T, Cerezo M, et al. Metformin inhibits melanoma development through autophagy and apoptosis mechanisms. Cell Death Dis 2011; 2: e199. 
8. Cazzaniga M, Decensi A, Pruneri G, et al. The effect of metformin on apoptosis in a breast cancer presurgical trial. Br J Cancer 2013; 109 2792-2797.

9. Marczak A, Bukowska B. New trends in the ovarian cancer treatment Prz Menopauzalny 2013; 6: 489-492.

10. Liu B, Fan Z, Edgerton SM, et al. Metformin induces unique biological and molecular responses in triple negative breast cancer cells. Cell Cycle 2009; 8: 2031-2040.

11. Wang LW, Li ZS, Zou DW, et al. Metformin induces apoptosis of pancreatic cancer cells. World J Gastroenterol 2008; 14: 7192-7198.

12. Hanna RK, Zhou C, Malloy KM, et al. Metformin potentiates the effects of paclitaxel in endometrial cancer cells through inhibition of cell proliferationand modulation of the mTOR pathway. Gynecol Oncol 2012; 125: 458-469.

13. Karczmarek-Borowska B, Zmorzyński Sz, Filip A. Biologiczna rola surwiwiny. Współcz Onkol 2008; 12: 437-440

14. Li F. Survivin study: what is thenext wave? J Cell Physiol 2003; 197: 8-29.

15. Fennell DA. Caspase regulation in non-small cell lung cancer and its potential for therapeutic exploration. Clin Cancer Res 2005; 11: 2097-2105.

16. Denel M, Marczak A. Panels od protein biomarkers and non-protein markers in the diagnosis of the ovarian cancer. Prz Menopauzalny 2013 17: 404-408.

17. Carmichael J, DeGraff WG, Gazdar AF, et al. Evaluation of a tetrazolium based semiautomated colorimetric assay: assessment of radiosensitivity. Cancer Res 1987; 47: 943-946.

18. Gasiorowski K, Brokos B, Kulma A, et al. A comparison of the methods applied to detect apoptosis in genotoxically-damaged lymphocytes cultured in the presence of four antimutagens. Cell Mol Biol Lett 2001; 6: 141-159.

19. Owen MR, Doran E, Halestrap AP. Evidence that metformin exerts its anti-diabetic effects through inhibition of complex 1 of the mitochondrial respiratory chain. Biochem J 2000; 348: 607-614.

20. Serkies K, Sinacki M, Jassem J. The role of hormonal factors and endocrine therapy in ovarian cancer. Wspolcz Onkol 2013; 17: 14-19.

21. Gottwald L, Danilewicz M, Fendler W, et al. The AgNORs count in predicting long-term survival in serous ovarian cancer. Arch Med Sci 2014 10: 84-90.

22. Woźniak S, Szkodziak P, Czuczwar P, et al. Ovarian tumor in women of the late childbearing age: how to assess the risk of cancer. Prz Menopauzalny 2013; 12: 78-82.

23. Rogala E, Nowicka A, Bednarek W, et al. Evaluation of the expression of the immunosuppressive enzyme - indoleamine 2,3-dioxygenase in ovarian cancer tissue. Prz Menopauzalny 2013; 12: 223-227.
24. Pawałowska M, Markowska A. The influence of metformin in the etiology of selected cancers. Wspolcz Onkol 2012; 16: 223-229.

25. Ferreira GD, Germeyer A, de Barros Machado A, et al. Metformin modulates PI3K and GLUT4 expression and Akt/PKB phosphorylation in human endometrial stromal cells after stimulation with androgen and insulin. Eur J Obstet Gynecol Reprod Biol 2014; 175: 157-162.

26. Shafiee MN, Khan G, Ariffin R, et al. Preventing endometrial cancer risk in polycystic ovarian syndrome (PCOS) women: could metformin help? Gynecol Oncol 2014; 132: 248-253.

27. Milewicz T, Kiałka M, Mrozińska S, et al. Metformin - new treatment strategies for gynecologic neoplasms. Przegląd Lekarski 2013; 70: 81-84.

28. Dilokthornsakul P, Chaiyakunapruk N, Termrungruanglert W, et al. The effects of metformin on ovarian cancer: a systematic review. Int J Gynecol Cancer 2013; 23: 1544-1551.

29. Zhang Z, Li S. The prognostic value of metformin for cancer patients with concurrent diabetes: a systematic review and meta-analysis. Diabetes Obes Metab 2014. doi: 10.1111/dom.12267 [Epub ahead of print].

30. Rattan R, Graham RP, Maguire JL, et al. Metformin suppresses ovarian cancer growth and metastasis with enhancement of cisplatin cytotoxicity in vivo. Neoplasia 2011; 134: 83-91.

31. Elmore S. Apoptosis: a review of programmed cell death. Toxicol Pathol 2007; 35: 495-516.

32. Yasmeen A, Beauchamp MC, Piura E, et al. Induction of apoptosis by metformin in epithelial ovarian cancer: involvement of the Bcl-2 family proteins. Gynecol Oncol 2011; 121: 492-498.

33. Portt L, Norman G, Clapp C, et al. Anti-apoptosis and cell survival: a review. Biochim Biophys Acta 2011; 1813: 238-259.

34. Dohi T, Beltrami E, Wall NR, et al. Mitochondrial survivin inhibits apoptosis and promotes tumorigenesis. J Clin Invest 2004; 14: 1117-1127.

35. Nair V, Pathi S, Jutooru I, et al. Metformin inhibits pancreatic cancer cell and tumor growth and downregulates Sp transcription factors. Carcinogenesis 2013; 34: 2870-2879.

36. Mckay TR, Bell S, Tenev T, et al. Procaspase 3 expression in ovarian carcinoma cells increases survivin transcription which can be countered with a dominant-negative mutant, survivin T34A; a combination gene therapy strategy. Oncogene 2003; 22: 3539-3547.

37. Zhang W, Chen X, Giu F. An antisense plasmid targeting survivin expression induces apoptosis and sensitizes hepatocarcinoma cells to chemotherapy. J Huazhong Univ Sci Technolog Med Sci 2003; 23: 387-391. 